\title{
Cloud Structure and Distributions over the Tropical Pacific
} Ocean

\author{
By \\ Joanne S. Malkis, University of California \\ and \\ Herbert Riehl, Colorado State University
}

Technical Paper No. 63

Department of Atmospheric Science

Colorado State University

Fort Collins, Colorado

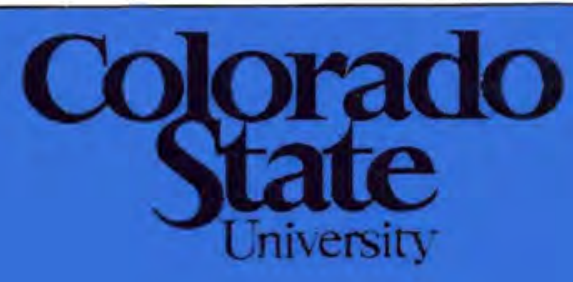

Department of
Atmospheric Science

Paper No. 63 


\title{
COLOBRADO STATE UNIVERSTTY

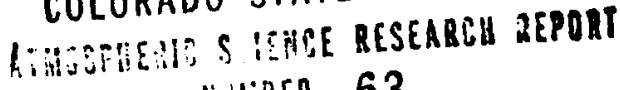 \\ Hüiner 63
}

\section{Cloud structure and distributions over the tropical Pacific Ocean ${ }^{1}$}

\author{
By JOANNE S. MALKUS, University of California, and HERBERT RIEHL, Colorado \\ State University
}

(Manuscript received October 29, 1963)

\begin{abstract}
During the summer of 1957 photographic cloud reconnaissance was carried out over the tropical Pacific Ocean, in order to observe tropical convection far from land influences, to relate the distribution of convective clouds to synoptic weather patterns and to analyze structure and street orientation of the cumuli. While all results, excepting photographic measurements, are qualitative, the following conclusions were obtained:

1. Areas with enhanced and with suppressed convection largely were determined by the synoptic situation, especially in the high troposphere.

2. Qualitatively, intensity of convection over large areas, say $10^{5} \mathrm{~km}^{2}$, could be deduced from application of the baroclinic vorticity theorem to high-and low-tropospheric flow.

3. Precipitation virtually was restricted to areas with synoptic build-up of the moist layer. Little, if any, precipitation fell from cumuli outside such zones, although maximum cloud height exceeded 10,000 feet frequently.

4. For the most part, cumuli were aligned in streets. Trade wind clouds were lined up along the wind in the lower moist layer, where wind and shear have the same orientation. Orientation of cloud rows at large angles to the low-level wind also was observed with lesser frequency, mainly when tall clouds extended into a mid-tropospheric layer with marked shear deviating from the wind direction.
\end{abstract}

\section{Introduction}

In the last several decades it has become evident that tropical convective clouds are not distributed randomly over the tropical oceans as once believed. Rather, they tend to occur in highly selective patterns. Total cloudiness, hence also the albedo, is likely to be less than given in present climatological charts.

Principal facts based on rainfall, aircraft and Tiros satellite observations are that on the synoptic (1000-mile) scale cloud distribution is related intimately to the distribution of thermo. dynamic and dynamic variables on this scale. Further, the clouds, even small trade wind cumuli, show marked organization into geometric patterns on the 10-100 mile scale. Finally, the vertical transport of heat from the surface layer to the upper troposphere may be accomplished effectively in a few large cumuli

\footnotetext{
1 Contributions to Meteorology No. 101, U.C.L.A., Department of Meteorology.
}

or "hot towers", numbering probably not more than $10^{3}$ to $10^{4}$ at any given instant in an equatorial belt of ten degrees latitude width (RIEHI \& MaLkUS, 1958).

Beyond such general statements and speculations, thorough observation and analysis of tropical oceanic cloud configurations for descriptive purposes and for assessing the role of these clouds in synoptic and general circulation weather processes has been undertaken only in a few hurricanes (Markus, Ronne \& Chaffee, 1961) and in a few trade wind samples (MaLkus, 1957).

With a view toward opening the exploration of cloud structure over the tropical oceans from a large-scale viewpoint, the Woods Hole Oceanographic Institution in the summer of 1957 undertook a photographic experiment in the tropical Pacific. Three roundtrips were made from Hawaii by an expert photographer, Mr. Claude Ronne. Using military aircraft flying at about 8000 feet altitude he took continuous

Tellus XVI (1964), 3

$19-642898$ 

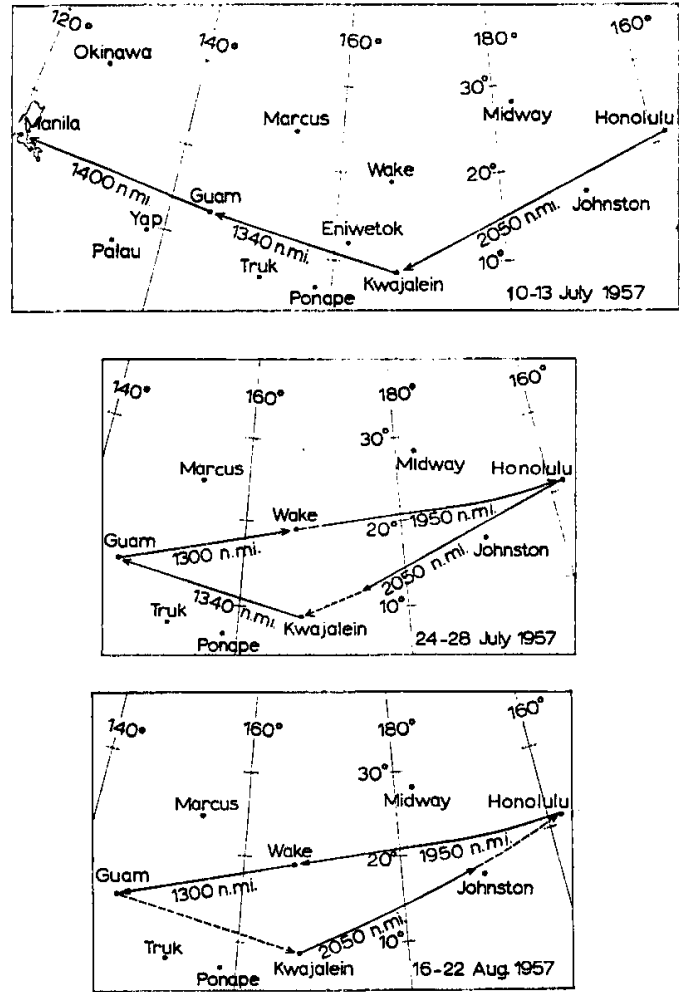

FIG. 1. Tracks flown in Pacific during summer of 1957. Dates according to GMT. Dashed portions of tracks in darkness.

motion pictures from one side of the aircraft and frequent still photos from the other side. Fig. 1 shows the tracks and the areas where the photographic equipment was operating, i.e. where the aircraft was in daylight. The data sample extends over more than $15,000 \mathrm{n}$. miles.

A large and excellent photographic record was obtained. As always in experimental work, there are shortcomings. Aircraft flying higher and faster would have been preferred; the density of upper-air data from ground stations could have been an order of magnitude greater; good coverage by a Tiros satellite would have been most welcome. Nevertheless, the undertaking yielded sufficient information to warrant presentation. This paper contains a summary of certain

1 For full information on all aspects of flights, analysis and photogrammetry the reader is reterred to "Cloud Structure and Distributions over the Tropical Pacific Ocean" by the same authors, to be published by the University of California Press as a hard-cover monograph late in 1964. results. ${ }^{1}$ At first, we shall describe a method for coding the whole sky as seen from aircraft. This is followed by a survey of large-scale features observed on the flights. Then, after more detailed discussion of one flight leg, organization of cloud streets and cloud shear will be taken up.

\section{Tropical whole sky code}

Much criticism has been voiced over the years about the tools available to observers for communication of their sky observations. Many suggestions have been made; but little has hap. pened to incorporate them in sky coding and communications. The purposes of many, if not most, recipients of sky information would be served most readily, if they were furnished with a single statement on sky condition over the whole sky visible from the observing point. Capability to make such statements was a prerequisite for the present study. Accordingly a whole sky code was developed with the objective of communicating the aggregate of the sky as seen from the aircraft in a comprehensive, yet simple and reproducible, system.

Over the oceanic tropics, we are concerned mainly with four primary types of sky, listed below together with their numbers in our code.

\section{Sky type}

Code Nos.

\section{Inversion}

Undisturbed easterlies without inversion $3-4$ Synoptic trade wind disturbance $\quad 5.9$ Strong synoptic disturbance 10-15

The detailed sky code, together with typical illustrations (Fig. 2), follows.

\section{Whole Sky Code}

0 - No clouds at all, or a few suppressed, or small numbers of very suppressed cumulus. Uppor cloud $1 / 10$ or less.

1 = Inversion-dominated: Trade wind cumulus spreading out into strato-cumulus, definite signs of stratiform cloud but total sky cover less than about one-half.

2 - Extensive strato-cumulus decks, more than about one-half total sky cover.

3 = Average trade cumulus sky, no particular organization. No significant upper clouds. No marked shear. Tops $8,000-10,000$ or less, little or no precipitation. 

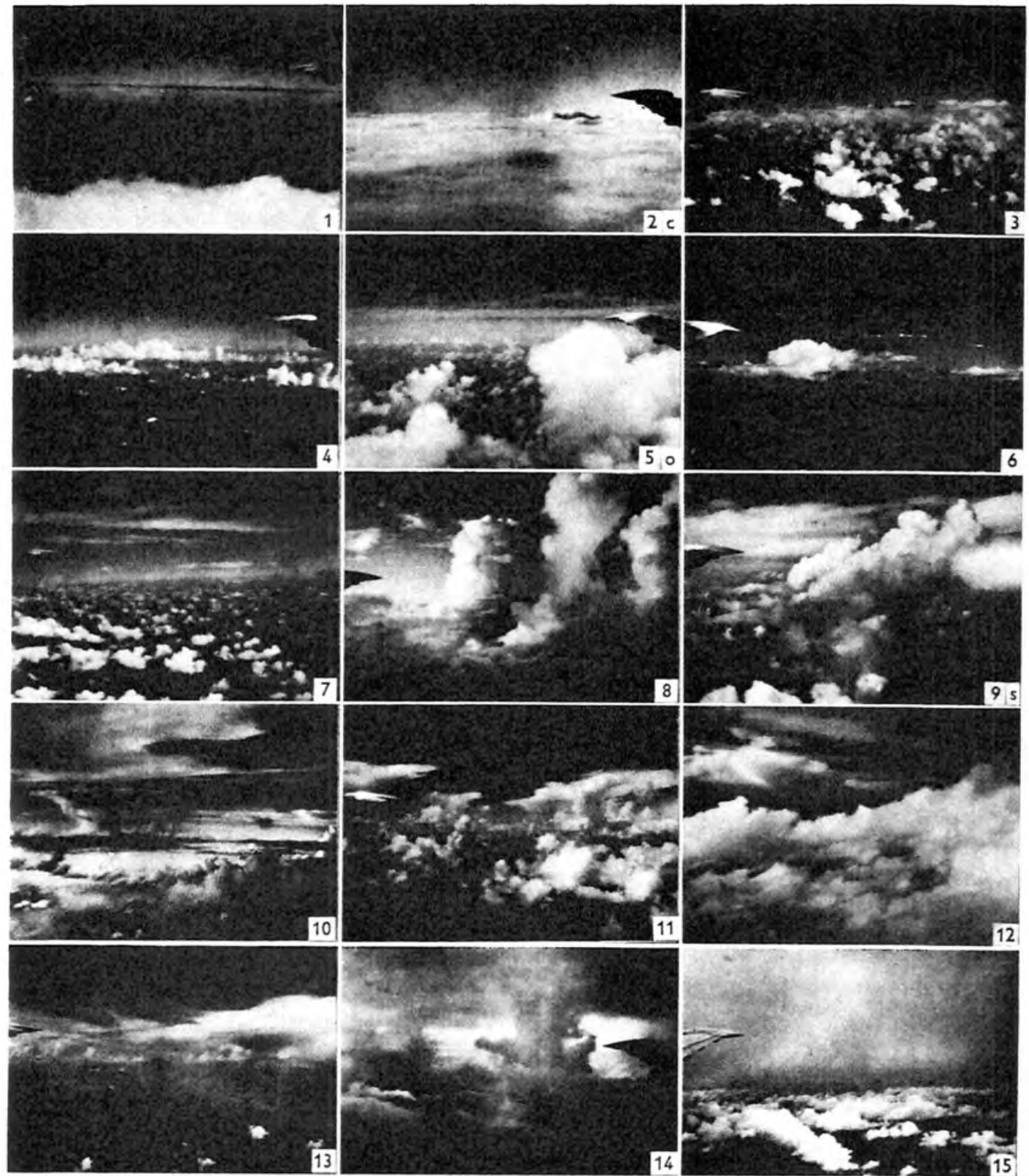

FIG. 2. Illustrating whole-sky code.

$4=$ Average trade cumulus sky, but with marked organization into rows or lines. No significant upper clouds. No marked shear. Tops $8,000-10,000$ or less. Little or no precipitation.

5 - Average trade cumulus sky with upper sheet clouds up to broken. No marked organization or shear. Little or no precipitation.

6 = Marked organization of convection, rather large convective clouds, even clouds with ice tops but not anvils, with adjacent extensive clear or almost clear areas. Upper sheets to broken.

Tellus XVI (1964), 3 
TABLE 1. Frequency (per cent) of cloud type occurrence.

\begin{tabular}{clcccc}
\hline & & & Code & & $\begin{array}{c}\text { Intervals with } \\
\text { precip. (per cent) }\end{array}$ \\
\hline Eastern & Per cent of all obs. & $0-4$ & $5-9$ & $10-15$ & 9 \\
area & Range on individuals legs & $28-88$ & $19-46$ & $0-30$ & 4 \\
Western & Per cent of all obs. & 23 & 34 & 43 & 24 \\
area & Range on individual legs & $0-75$ & $5-84$ & $0-100$ (typhoon) & \\
\hline
\end{tabular}

Intervals with precipitation are defined as the percentage of 15 -minute flight periods with precipitation out of all 15-minute flight periods in daylight.

7 - Suppressed trade cumulus sky with upper sheets broken or overcast but not precipitating. No marked shear or organization.

$8=$ Above average cumulus activity, high tops, occasional cumulus congestus. Showers. Upper cloudiness less than broken. No marked shear or organization.

$9=$ Above average cumulus activity, high tops, cumulus congestus. Showers. Upper cloudiness broken to overcast. No marked shear or organization.

10 = Occasional cumulonimbus, no obvious organization, no significant or extensive independent upper sheet clouds.

I I = Rows or suspected organization of cumulonimbus, no extensive or significant independent upper clouds.

12 Cumulonimbus and partial coverage by cirrus, altostratus and/or altocumulus.

13 - Substantial upper cloud coverage, sup. pressed convection over wide clear areas, except some cumulonimbus visible. No precipitation from upper clouds.

14 - Rain from upper sheets (overcast or almost overcast) cumulonimbus indistinct.

15 = Upper overcast raining, no cumulonimbus seen or suspected, suppressed low level convective activity.

\section{Postscripts}

$a=$ Marked organization into rows or lines.

$s=$ Marked shear.

$c=$ Apply to 1 or 2 if cumulus tops penetrating stratus.

$d=$ Distant disturbance-high clouds low on horizon.

$-=$ Weaker than normal for category.

\section{Survey of results}

Climatically, over the area covered by the flights, the trade wind inversion and dry conditions prevail in the eastern portion in summer, while the western parts experience much cloudiness, precipitation and tropical storms. The transition zone roughly lies near $170 \mathrm{E}$ longitude; of course strong aperiodic departures from the average state occur commonly.

Of ten missions executed during daylight west of Hawaii, five yielded observations over the eastern half of the climatic regime; the other five covered the western half (Fig. 1). Table 1 summarizes the cloud forms encountered.

Total time occupied by the flights was less than 100 daylight hours, so that unrepresentative sampling might be feared. But the climatic difference between east and west is well brought out in Table 1. Further, considerable variability of cloud structure and amount was encountered on individual flight legs. This is a feature in agreement with other observations of recent years, but contrary to the classical picture of steady tropical wind systems with random convection. We may conclude, that the time and space sampling performed by the aircraft appears to have been satisfactory in the first approximation in establishing the climatic pattern of cloudiness and its variability.

Precipitation: From Table 1 the main difference between east and west lies in the absence of cumulonimbus systems in the east, whereas clouds typical of trade wind disturbances were equally frequent in both parts. Virtually no precipitation fell from trade wind clouds, even though the top of the tallest clouds exceeded 10,000 feet on most flight legs, especially west of $170 \mathrm{E}-180^{\circ}$ longitude. All 
noteworthy precipitation was concentrated in synoptic-scale disturbances with widespread occurrence of at least cloud codes 6,8 and 9 . This observation differs markedly from experience on and close to tropical islands where clouds only a few thousand feet thick may yield heavy showers. Over the ocean such clouds have been observed to precipitate only within the setting of a synoptic convergence zone.

Enhanced convection and synoptic disturbances: Several stretches 100-200 miles long were flown in the east where definite swelling up of the trade wind cumuli occurred. On account of upper dryness and thermal stability these clouds could not break through to high altitudes and form cumulonimbus, though some of them tried. Novertheless the disturbed areas, as far as one can judge, were associated with troughs in the high troposphere rather than with pronounced disturbances of the lower trade wind belt.

Fig. 3 depicts a typical instance. The aircraft, moving northeastward from Kwajalein, at first encountered nearly clear skies, then an area with cloud code 7-9 about 200 miles wide, followed by return to small trade wind clouds. At the surface normal high pressure prevailed. Location of an area with maximum cloudiness east of an upper trough in a westerly current, with clearing to its west, is typical of what is normally observed in middle latitudes and also in the tropics, given this type of upper current. Reasoning qualitatively with the theorem of conservation of potential vorticity, high-level air overtaking the trough from the west will gain cyclonic absolute vorticity, hence converge laterally and spread vertically. Since the convergence is situated in the high troposphere, the vertical spreading must be downward and the upper convergence must be balanced by low-level divergence for a nearly steady pressure field. East of the trough line the reverse occurs. This reasoning is capable of explaining the weather distribution of Fig. 3 in general terms. It is remarkable that there appears to be a distinct reaction by the clouds--.-with highest tops near 14,000 feet-to the trough in the upper troposphere, while the lower convergence had no apparent effect on the isobaric field. This, however, may be a somewhat deceptive conclusion in a region with very sparse data. Certainly, cloud orientation rotated counter-

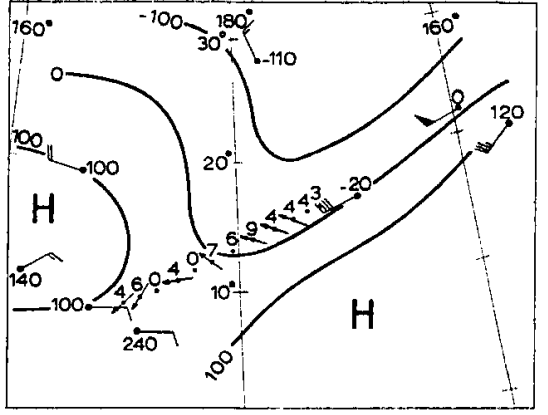

Frg. 3. Mean winds $(\mathrm{kn})$ and altimeter correction with respect to mean tropical atmosphere (feet) for layer 250-150 mb, 22 August 1957, 00 GMT. Cloud code along flight route (subscripts omitted) and orientation of cloud rows.

clockwise from east to west across the upper trough.

In addition to this class of disturbance other cases were found with similar high-tropospheric flow but with wave-like flow in the low levels. On the first mission of the series, the aircraft encountered a convective zone in about the same area as in Fig. 3; on this occasion the trade exhibited a wavelike structure (Fig. 4). The turning of cloud row orientation was even sharper than the turning of wind as far as can be ascertained (Fig. 5). Cloud tops attained 24,000 feet along the flight path; one cumulo. nimbus extending to 50,000 feet was sighted in the distance. The high tropospheric flow (Fig. 6) resembles that of Fig. 3. However, the disturbed weather zone and lower trough axis are located far east of the upper trough; they are not connected with it. Reasoning on the basis of con-

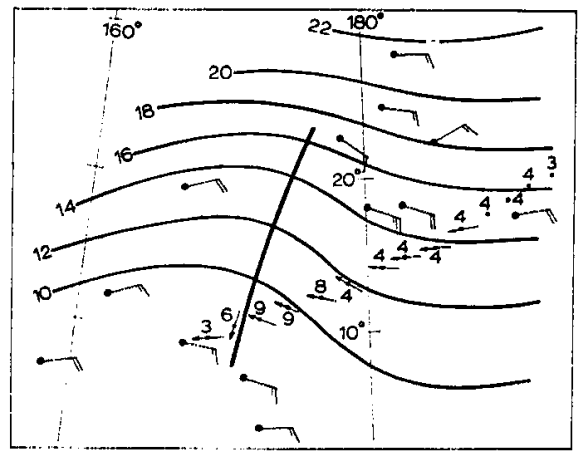

FIG. 4. Low-level winds (kn) and isobars (mb, first two digits omitted), 11 July 1957, 00 GMT. Cloud code along flight route (subscripts omitted) and orientation of cloud rows. 


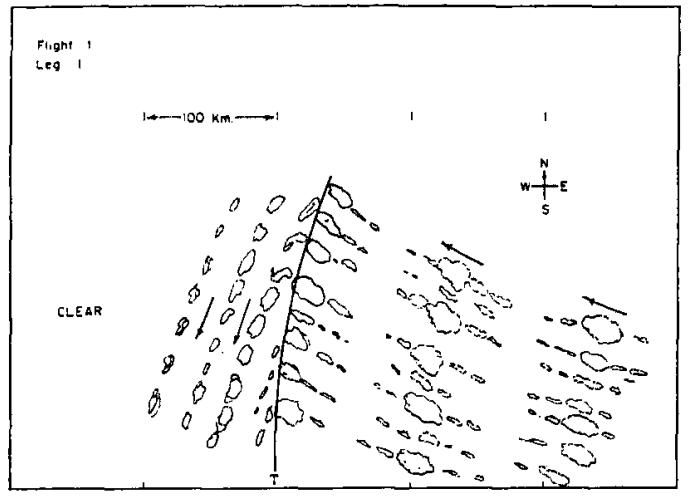

FIa. 5. Sketch of cloud observations near wave trough of Fig. 4.

servation of potential vorticity again leads to the correct picture of cloudiness distribution, and it can be reinforced in this case by similar reasoning applied to the wave in the lower easterlies (RIEHL, 1945). This wave subsequently moved underneath the upper trough located farther west in Fig. 6; it then weakened considerably as it passed under the area of upper convergence associated with the high-level trough.

Figs. 7-8 present still another variant of the same theme, observed several hundred miles north of the disturbance just described on a flight five weeks later. In this instance the convective area was broad, with great arrays of cumulonimbus and very disturbed conditions. Scanty high-level data suggest flow structure similar to that of Figs. 3 and 6. The main difference between the three disturbed zones appears to lie in the amplitude of the low-tropospheric flow pattern with attendant convergence of the trade winds.

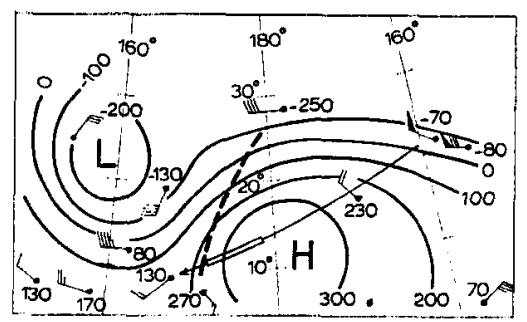

Fra. 6. Mean winds $(\mathrm{kn})$ and altimoter correction with respect to mean tropical atmosphere (feet) for layer 250-150 mb, 11 July 1957, 00 GMT. Heavy dashed line is wave trough from Fig. 4. Flight track indicated by line with arrow; main area of build-ups marked with double line.

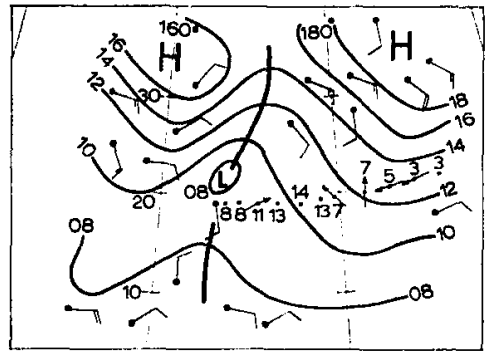

Fig. 7. Low-level winds (kn) and isobars ( $\mathrm{mb}$, first two digits omitted), 17 August 1957, 00 GMT. Cloud code along flight route (subscripts omitted) and orientation of cloud rows.

Suppressed convection: In addition to the relation of disturbed cloud structure to the broadscale flow patterns, the frequent suppression or total absence of cumuli was a significant feature of the flight record. Large clear areas are not expected over the tropical oceans in summer; yet they were observed. Outstanding was a clear area 300 miles wide west of Hawaii associated with regular easterly trade slowly curving clockwise. Cloud rows gradually diminished in height as the aircraft approached this area. Cloud thickness thon became minute and was followed by a wide expanse of cloudless and hazy sky.

The high-level data suggest a cold-core Low over the area; but analysis is too speculative for presentation. In general, correlation between such Lows and suppressed cloudiness was noted on all flights, even in the area between the Marshall and Marianas Islands. One of the situations encountered there will now be described in more detail.

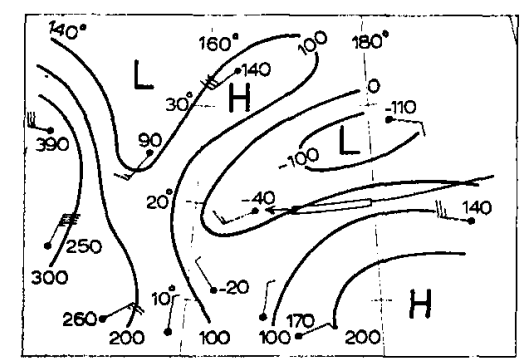

FIG. 8. Mean winds (kn) and altimeter correction with respect to mean tropical atmosphere (feet) for layer 250-150 mb, 17 August 1957, 00 GMT. Flight track indicated by line with arrow; main area of build-ups marked with double line. 


\section{Flight from Kwajalein to Guam, 25-26 July 1957}

Low troposphere: Of the legs flown by the aircraft, that between Kwajalein and Guam is most satisfactory from the standpoint of upperair sounding density. Five stations are located on or relatively close to the track (Fig. 1). The example chosen, 25-26 July (GMT), is remarkable in that little of importance on the synoptic scale was taking place in the low levels, considering the location and time of year. There was no equatorial low pressure trough with counter currents; pressure was near the seasonal mean, with isobars normally oriented. In correspondence, low tropospheric winds were blowing from east or slightly south of east without noticeable amplitude along the flight track (Fig. 9). From time continuity one can merely detect a slow change from cyclonic to anticyclonic flow curvature from 24 hours before to 24 hours following the flight. Wind speed decreased from 20 to 10 knots from eastern to western flight terminus. The low-level vertical wind structure on the Eniwetok atoll (Fig. 10) was typical for the trades: invariant wind direction from the ground to the top of the cumulus layer and beyond, with easterly wind speed relatively constant through the moist layer and finally decreasing upward.

Corresponding to the indifferent low-level situation the aircraft found no area with disturbances similar to those of Figs. 4 and 7 . Yet marked variation in cloud type and structure occurred, and some of the most spectacular clouds noted during the whole flight program were observed.

Cumulonimbus, isolated and occasionally in widely spaced rows, marked the first 300 miles (Fig. 9). Near Eniwetok, with abrupt cessation of the tall clouds, the orientation of the low cumulus rows changed from slightly south of east to slightly north of east. Then the low clouds almost died out for considerable distance while some cirrus, mainly at the horizon, remained.

Subsequently, rows with very strongly slanting clouds were observed near the middle of the flight leg. These were indeed spectacular; Fig. $11 b$, a composite of several time-lapse photographs, shows one of these clouds with horizontal extent near 40 miles. Though extending up to 35.000 feet, these clonds have been coded as

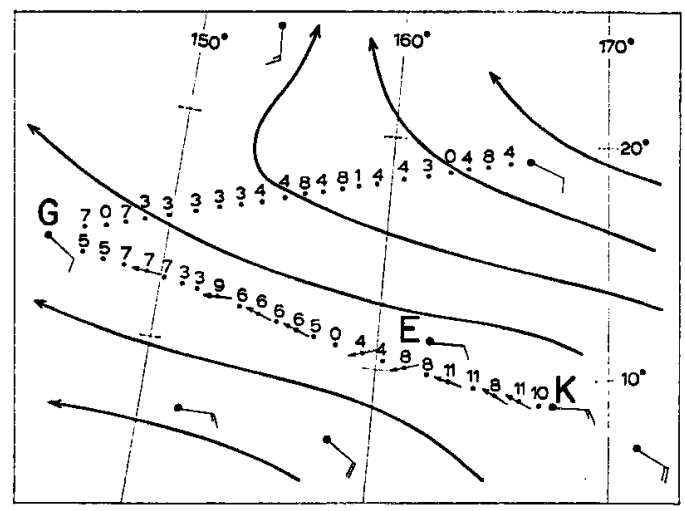

Fra. 9. Low-level winds $(\mathrm{kn})$ and streamlines, 26 July 1957, 00 GMT. Cloud code (subscripts omitted) for this flight and for flight made next day from Guam to Wake. $K$ denotes Kwajalein, $G$ Guam and $E$ Eniwetok.

No. 6. Return to trade wind skies, with some evidence of suppression of cumulus development, completed the flight leg.

In view of the slowly changing synoptic situation the cloud code for the Guam-Wake flight on the next day also is shown. We observe little variation in pattern and a complete lack of large cloud systems.

As commonly noted over the western parts of the tropical oceans, thermodynamic analysis does not provide a satisfactory answer to the observed cloudiness variation. Typical of all soundings taken near flight time, and typical of soundings found in general in the rainy season over the western parts of tropical oceans, is the ascent at Eniwetok (Fig. 12). The lapse rate lies between the dry and moist adiabatic to about $400 \mathrm{mb}$, then stabilizes slowly upward. The moisture trace shows a decided minimum

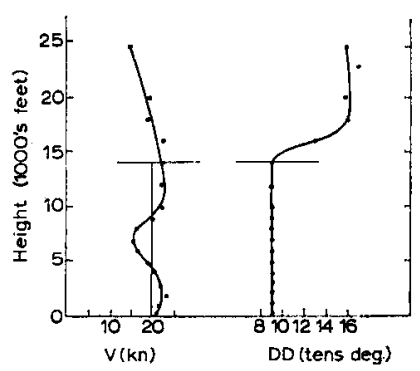

FIG. 10. Vertical distribution of wind speed and direction at Eniwetok, 26 July 1957, 00 GMT. Horizontal lines mark top of layer with trade wind.

Tellus XVI (1964), 3 


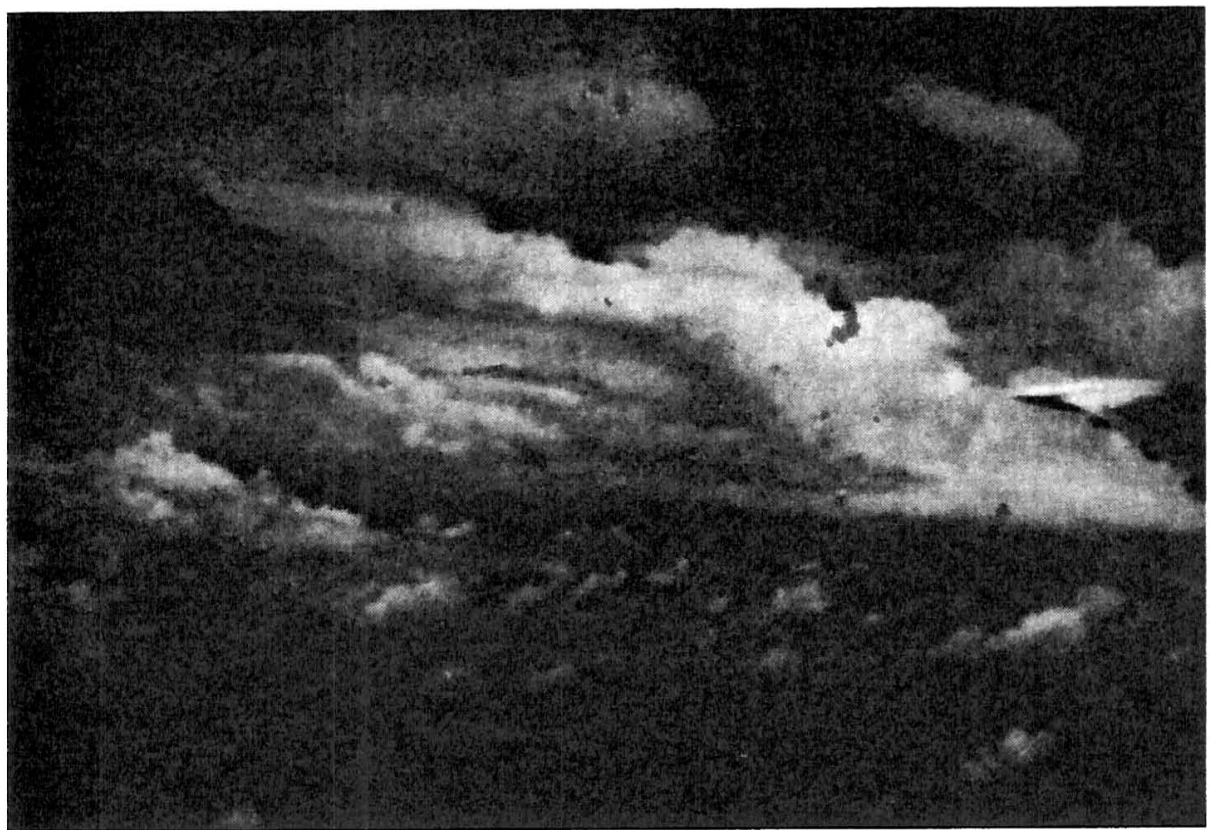

$11 a$

near $700 \mathrm{mb}$, suggestive of subsidence, yet without stabilization of temperature lapse rate. The only really interesting feature is that the sounding was about $1^{\circ} \mathrm{C}$ colder than the others; Eniwetok was situated at the edge of a coldcore Low aloft.

Upper troposphere: Our examination now turns to the upper troposphere. Frequently a large shearing layer is found in the middle and high troposphere; this certainly was the case in our example. Fig. 13 shows the principal shear vector at the rawin stations. In addition," the difference in altimeter correction between the 1000 - and $200 \cdot \mathrm{mb}$ surfaces has been entered using station data as well as surface and 200 -

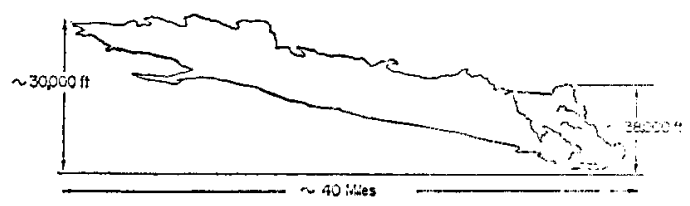

$11 b$

Fig. 11. Convective clouds near middle of track in Fig. 9. (a) Frame from ciné film showing nearest cloud in westernmost row. (b) Composite tracing from several frames in ciné film showing tallest cloud in row second from east (see Fig. 15). Height seale expands to left as anvil slants toward camera. mb analyses. Clearly, we observe cyclonic circulation increasing upward about a cold core. In terms of temperature gradient the pattern of Fig. 13 is weak, since a thickness difference of 200 feet for the layer 1000-200 mb corresponds to a mean virtual temperature difference only of about $1.25^{\circ} \mathrm{C}$. Nevertheless, the cold core is strong enough for the existence of a rather elongated cyclone to be shown in the high troposphere (Fig. 14), with intense counterclockwise circulation.

Discussion: Tropical high-tropospheric cyclones have been described frequently (cf.

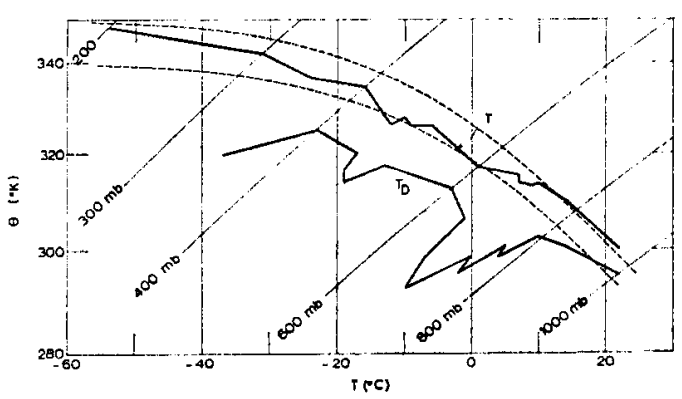

Fig. 12. Tephigram of radiosonde ascent at Eniwetok, 26 July 1957, 00 GMT. Vertical lines are isotherms, horizontal lines isentropes, curved lines more or less parallel to sounding are moist adiabats. 
Rieht, 1958; Palmer, 1951; Simpson, 1952). The interesting fact is that, though normally their circulation vanishes downward at about $500 \mathrm{mb}$, they can nevertheless affect lower cloud structure profoundly. This is very clear in our case, where there was no evident lowlevel disturbance. In general, the cold core was associated with relatively dry air, with precipitable water content $1-2 \mathrm{~cm}$ below that of the surroundings. This agrees with the overall absence of any strong convection and precipitation on the Kwajalein-Guarn and Guam-Wake flight legs (Fig. 14).

In this general setting, the rows of strongly slanting clouds traversed by the aircraft may be regarded as meso-structural features. Granted the analysis of Fig. 13, these clouds occurred in an area of strong westerly shear and of coldest mean temperature along the flight route. Both to east and west of the area, where the two parameters coincided in this sense, cloudiness, even low cloudiness, tended to be suppressed. Further, on the Guam-Wake leg there were no such clouds. Due to slow southward drift of the vortex with time, that flight leg remained north of the cold core; vertical wind shear was moderate easterly over the western part of the flight route and became small and variable over the eastern portion.

It appears then that the slanting clouds were generated in an environment with enhancement of thermodynamic instability plus large vertical shear suggestive of strong baroclinity. From the vorticity standpoint, the situation is difficult to analyze. Probably, the air in the clouds moved from an environment with nearly zero relative vorticity into one with pronounced cyclonic vorticity. Again noting the scant data on which Fig. 13 is based, the geostrophic shear as drawn is 100 knots or about twice the actual shear. Unless strong frictional forces in and near the clouds themselves are invoked, as suggested by GRAY (1962) for hurricanes, a cyclonic radius of trajectory curvature of $500 \mathrm{n}$. mi. is computed at $200 \mathrm{mb}$ from the gradient wind equation. It is assumed that the difference in shear equals the difference between actual and geostrophic wind at $200 \mathrm{mb}$. On account of the slowly changing synoptic pattern, this number may be taken as a first approximation to the radius of streamline curvature. Taking the 200 $\mathrm{mb}$ velocity as $50 \mathrm{knots}$, the curvature term in the expression for vorticity is 0.1 per hour or

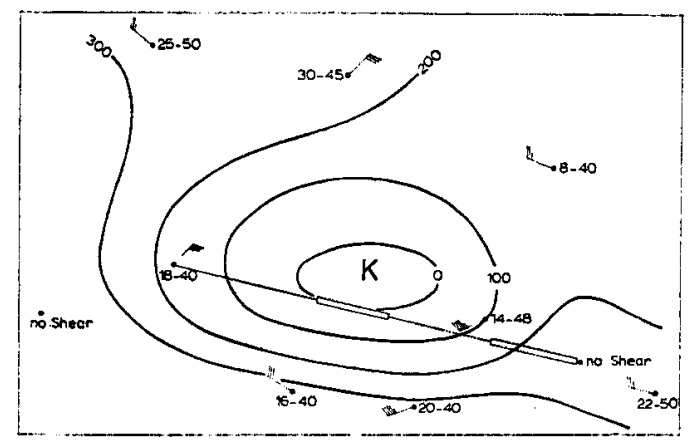

Fia. 13. Shear (kn) between top of trade wind layer and high troposphere; altitude interval marked in 1000 's feet. Analysis shows thickness deviation from mean tropical atmosphere (feet) for layer 1000-200 mb. Enhaneed convection zone along flight track marked by double line.

about the same as the vaiue of the Coriolis parameter. Unless anticyclonic shear of 10 knots per 100 miles is present-certainly not suggested by Figs. 13 and 14 -the ascending particles acquired increasing cyclonic vorticity to the top of the cloud. Since the cloud ended in this particular environment, there is an interesting question whether the levelling off of the cloud funnel with height is proscribed dynamically by the baroclinic vorticity theorem. Alternately, of course, more complete forms of the vorticity equation may be explored. Since precise information was lacking on the atmospheric variables in the area of the clouds, this interesting topic cannot be pursued further.

Regarding the change in upper cloud pattern near Eniwetok, we cannot advance a definitive hypothesis. Superficially, the change is similar

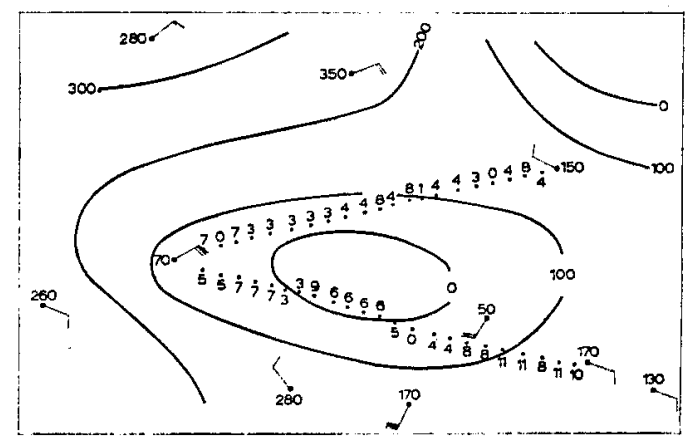

Fic. 14. Mean winds $(\mathrm{kn})$ and altimeter correction with respect to mean tropical atmosphere (feet) for layer 250-150 mb, 26 July 1957, 00 GMT. Cloud code from Fig. 9. 
to that found when passing through a wave trough in the easterlies. However, there is no backing for such a construction in the instantaneous wind field at low levels or in the time sequence, even though the cloud row orientation rotated. Possibly the strongest southwesterly flow in the high troposphere was located near Eniwetok. Then air to the east would have ascended toward decreasing and air to the west toward increasing cyclonic vorticity. Again invoking the vorticity theorem, tall convection would have been facilitated dynarnically east and suppressed west of Eniwetok. This, however, remains conjecture in the absence of detailed observations.

\section{Cloud streets}

One of the striking aspects of the cumulus populations observed during all flight missions was their organization into streets or rows, observed on the majority of photo prints analyzed at about 15-minute intervals of flight time (50 miles). During some portions of the flights, however, organization was far more pronounced than on others; randorn cloud distribution was encountered in some places.

Qualitatively, a scale of four classes of intensity of organization was established. Omitting periods without cumuli and with aircraft in cloud, the four classes were represented over the entire data sample on a per cent basis as follows:

\section{Organization}

scale:

Absent Weak Moderate Strong

Per cent

$$
\text { occurrence: }
$$$$
30
$$$$
35
$$

The degree of organization was not ordered by area or by vertical extent of cumuli. It should be noted that observations from high flying jet aircraft or from satellites have shown organization on larger distance scales not observable under the given experimental conditions.

From theoretical and experimental work (cf. Avsec, 1939, and others) organization is expected to be linked at least to heat exchange between sea and air, thermal stratification and wind structure of the atmosphere. Our experiment was not designed to measure these variables in detail. It was undertaken mainly for the purpose of obtaining a broad survey of types and degrees of organization found over ocean areas far from any land. Two directional modes of organization stood out: frequent alignment of cloud streets parallel to the low-level wind, and less frequent alignment at large angles to this wind, not necessarily, however, at right angles.

Parallel mode: The trade wind current generally is heated from below, and within the cloud layer wind direction normally is nearly invariant with height. Moreover, in the area and time of year under study, wind speed also is relatively constant above the subcloud layer and lowest part of the cloud layer (Fig. 10). Thus, clouds limited to the trade wind moist layer mainly are acted upon by shear at their lower boundary, and this shear is parallel to the wind direction. Given the hypothesis that cloud streets are longitudinal, i.e., oriented along the shear of the wind, the streets also should be parallel to the trade wind flow itself. This hypothesis was well borne out; nearly all row organization of the trade wind cumuli was along the wind. Cloud thickness was immaterial; some of the finest rows were associated with cumuli at most a few thousand feet thick.

Spacing of rows had the order of cloud thickness and increased with cloud thickness. At the approach to disturbed zones, such as shown in Fig. 5, spacing widened from 3-4 km to about $30 \mathrm{~km}$; thus the ratio of dopth of moist layer to distance between cloud streets remained constant within a factor of two.

The parallel mode also was well developed in the upper portions of tall clouds extending well into the strong upper shear layers that frequently were observed. Such alignment has been observed in cumulonimbi at all latitudes.

Cross-wind mode: Cloud alignment at some angle to the low-level wind was observed mainly in the presence of clouds coded 6,9 , or higher. In Fig. 5 this alignment is portrayed by the appearance of a more or less sinusoidal variation in the depth of the cumuli in the parallel streets. A more extreme case is that of the large slanting clouds described earlier. Here the cross-wind mode dominated completely for the line-up of tall clouds (Fig. 15). Only the small cumuli, perhaps not more than 2000 feet thick, still had parallel alignment in an environment with positive shear, i.e., clouds leaning downwind with increasing height. All important clouds, numbering about 25, are mapped to scale in Fig. 15. While the orientation of the long necks 


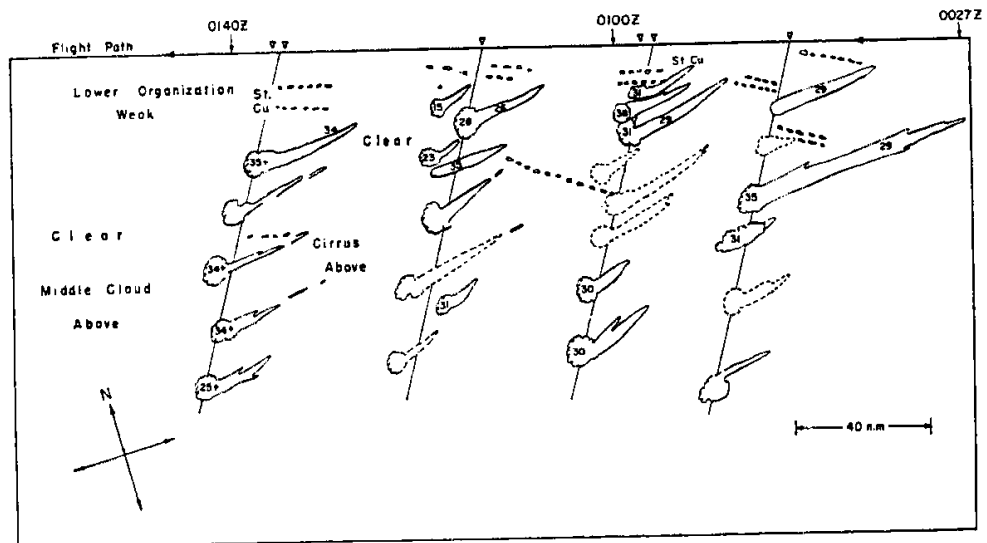

Fra. 15. Horizontal projection of principal clouds and streamers along middle of flight route in Fig. 9. Tops indicated in 1000's feet. Orientation of lower clouds also shown.

agrees with that to be expected from Fig. 13, namely slightly south of west, the four cloud streets themselves extended from NNE to SSW.

The wind profile of Fig. 10 may suggest a correlant for this orientation, supported also by the balloon ascent at Truk, located some distance south of the cumulus streets. Commonly, there are two different wind regimes in the tropical troposphere, as illustrated in Figs. 4-6 and in Figs. 9 and 14. Between these layers the flow normally is weak and the wind hodograph passes from lower to upper layer through the origin of the graph. In Fig. 10, however, the wind turns clockwise from lower to upper current at a speed of $20 \mathrm{knots}$; the shear vector connecting low and high troposphere is parallel to the orientation of the cloud streets of Fig. 15. Although the shearing layer is shallow and has

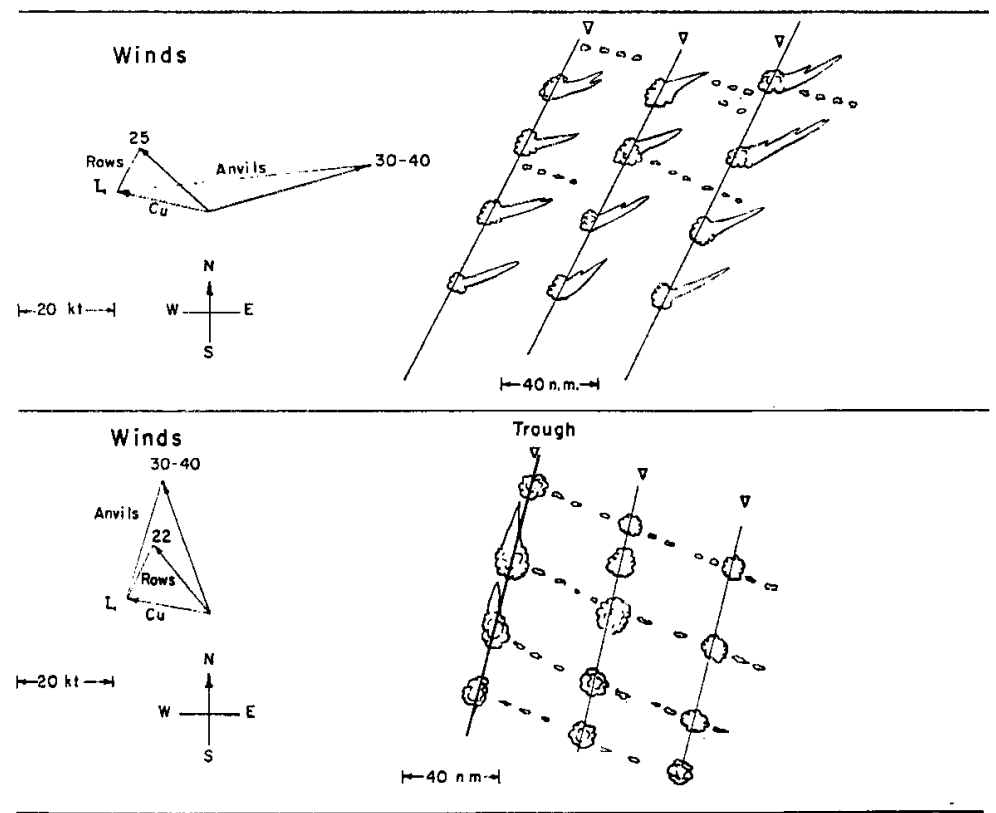

Fra. 16. Schematic summary of cloud organization shown in Figs. 5 and 15. Wind hodographs, shear layers and relation to cloud and row orientation shown on left. Lower trade arrow labelled "L". Level of upper wind arrows noted in 1000's feet at arrow ends.

Tellus XVI (1964), 3 
a high base, it may nevertheless be a factor of importance for the orientation of the rows. Altogether, we see three orientations in Fig. 15: the low cumuli, parallel to the trade; the major rows of tall clouds, parallel to the mid-tropospheric shear vector; and the necks protruding from these clouds, parallel to the shear vector above $450 \mathrm{mb}$, approximately.

The proposed scheme is illustrated further in Fig. 16 for the cloud arrangements of Figs. 5 and 15 .

It is of interest to add that, on a few stretches, the trade cumuli also exhibited the cross-wind mode. As far as can be determined, a midtropospheric shearing layer of the type seen in Fig. 10 existed on these occasions and had a base well down within the trade wind moist layer, thus acting on the cumuli. Further, street alignment was not observed in all disturbed synoptic zones. On two legs there was very little organization over large stretches with extensive cumulonimbi. As near as can be determined, wind speed at low levels was very weak on these occasions. As suggested by Woodcock (1942), there may be a lower limit for wind speed near the surface, if organization is to occur. Rows often are found when trade wind speed is near or above average; they were observed in all disturbances where strong winds prevailed.

\section{Conclusion}

Our study had the nature of a large-area oceanic survey. In consequence, the variables having bearing on cumulus-forming processes could not be observed in any detail so that results, for the most part, are qualitative. The following statements may be made:

1. Cloud structure in general was strongly controlled by the synoptic situation, especially the high-tropospheric flow. Wind patterns near $200 \mathrm{mb}$ influenced cloud structure on several occasions in the absence of pronounced lowtropospheric disturbances.

2. Qualitatively, cloud structure should be deduced from low- and high-tropospheric flow, or even from the latter alone, through application of the baroclinic vorticity theorem. Area build-ups of cumuli occurred in regions of (inferred) high-tropospheric divergence; cumuli were suppressed, and in several instances skies cleared completely, in areas of high-tropospheric convergence. Random convection to great heights occurred nowhere. Intensity of convective activity was enhanced when a lowtropospheric wavelike disturbance in the easter. lies was connected with a high-tropospheric flow pattern conducive to upper divergence.

3. Precipitation was restricted mainly to the areas with synoptic build-up of the moist layer. Little, if any, precipitation fell from cumuli outside such zones, although maximum cloud thickness exceeded 10,000 feet frequently. This points to an important role of synoptic-scale convergence in maintaining the moisture supply for cloud chimneys requisite for droplet growth to precipitation size. CRessman (1946) has discussed the importance of low-level convergence for cloud growth from a somewhat different, though entirely relevant, viewpoint by considering net mass indraft superimposed on convection originating according to the "slice method" development.

(4) For the most part, cumuli were aligned in streets, with spacing proportional to cloud thickness. Trade wind clouds were lined up along the wind in the moist layer, where wind and shear have the same orientation. Anvils and other protrusions from tall clouds were oriented parallel to the shear roughly between 500 and $200 \mathrm{mb}$. Orientation of cloud rows at a large angle to the low-level wind also was observed on less frequent occasions when a marked mid-tropospheric shearing layer was present or when the shearing layer separating low-and high-tropospheric flow extended well into the trade wind moist layer. On a few occasions, parallel and crosswind modes of orientation were superimposed.

In the absence of detailed wind and other relevant data, not all variations of organization encountered could be explained. It may be stated, however, that organization appeared to be weak or absent with very low trade wind speeds. Further, organization did not depend on cloud thi.kness. These results agree with the findings of many observers of tropical clouds as expressed in the literature over the last century. The main value of the study is thought to lie in the examination of these findings, often derived from data samples near land areas, through a comprehensive survey over large oceanic areas far from any land influence. 


\section{Acknowledgement}

Principal acknowledgment is due to $\mathrm{Mr}$. Claude Ronne who carried out the photographic missions. Mr. William M. Gray, Colorado State University, participated in the synoptic ana- lysis program. Much of the cloud data reduction and analysis work was performed by Miss Margaret Chaffee.

This research was sponsored by the Office of Naval Research and the United States Weather Bureau.

\section{REFERENCES}

Avsec, D., 1939, Thermoconvective eddies in air. Application to Meteorology, Scientific and Technical Publications of the Air Ministry Works of the Inst. of Fluid Mech. of the Faculty of Sciences at Paris, No. 155. Published (in French) at Ed. Blondel la Rougery. 7, Rue St. Lazare, Paris.

Cressman, G. P., 1946, The influence of the field of horizontal divergence on convective cloudiness. J. Meteor., 8, p. 85.

Gray, WM. M., 1962, On the balance of forces and radial accelerations in hurricanes. Quart. J. Roy. Meteor. Soc., 88, p. 430.

Markणs, J. S., 1957, Trade cumulus cloud groups: Some observations suggesting a mechanism of their origin. Tellus, 9, p. 33.

Malkus, J. S., Ronse, C., and Chafree, M., 1961, Cloud patterns in hurricane Daisy, 1958. Tellos, 13, p. 8.
Palmer, C. E., 1951, On high-level cyclones originating in the tropics. Trans. Amer. Geoph. Union, 32, p. 683.

RIEHL, H., 1945, Waves in the easterlies and the polar front in the tropics. Dept. Meteor. Univ. Chicago, Misc. Rep. No. 17,

RIEHL, H., 1948, On the formation of typhoons. J. Meteor., 5, p. 247.

RIEHL, H., and MaLKUS, J. S., 1958, On the heat balance in the equatorial trough zone. Geophysica, 6, p. 503.

Simpson, R. H., 1952, Evolution of the Kona storm, a subtropical cyclone. $J$. Meteor., 9, p. 24.

Woodcock, A. H., Soaring over the open sea. Seientific Monthly, 65, p. 226. 